\title{
Transfusão de hemácias em pacientes falcêmicos
}

A anemia falciforme é uma doença prevalente no Brasil, e é caracterizada por uma mutação genética que provoca uma deformidade nas hemácias do portador, causando diversos problemas. Uma boa parte desses pacientes necessitam de transfusões frequentes para tratamento de complicações da doença, porém, ao longo do tempo podem surgir complicações resultantes dessas transfusões, o que torna o uso dessa terapia bastante criteriosa. Mas por que o paciente falciforme pode apresentar problemas com a terapia transfusional? Devido a frequência de transfusões, o paciente falcêmico pode sofrer uma aloimunização contra antígenos de vários sistemas de grupos sanguíneos. A melhor forma de prevenir esse tipo de reação é realizando a fenotipagem das hemácias para teste de compatibilidade. O presente estudo teve como objetivo abordar sobre a transfusão de hemácias em pacientes falcêmicos, elencando também as reações que podem ocorrer em função dessa terapia e os procedimentos que devem ser tomados para evitar tais reações, abordando também o papel do biomédico nesse processo. Trata-se de uma pesquisa literária realizada com base em artigos científicos nacionais e internacionais, monografias, leis e livros que foram selecionados utilizando como critério a abordagem do tema escolhido. Foram utilizados como fontes de pesquisa os sites SCIELO (Scientific Electronic Library Online), Pubmed, Biblioteca Virtual do Ministério da Saúde e livros presentes na biblioteca física e virtual do Instituto Educacional Santa Catarina (IESC). A terapia transfusional é uma ótima opção de tratamento das complicações da anemia falciforme, porém devem ser utilizadas medidas para prevenir os problemas pós-transfusionais.

Palavras-chave: Anemia Falciforme; Aloimunização; Transfusão.

\section{Red blood cell transfusion in sickle cell patients}

Sickle cell anemia is a prevalent disease in Brazil, and is characterized by a genetic mutation that causes deformity in the red blood cells of the carrier, causing several problems. A good part of these patients needs frequent transfusions to treat complications of the disease, but over time there may be complications resulting from these transfusions, which makes the use of this therapy very careful. But why can sickle cell patients have problems with transfusion therapy? Due to the frequency of transfusions, the sickle cell patient may be alloimmunized against antigens from various blood group systems. The best way to prevent this type of reaction is to perform red cell phenotyping for compatibility testing. The present study aimed to address the red blood cell transfusion in sickle cell patients, also listing the reactions that may occur due to this therapy and the procedures that should be taken to avoid such reactions, also addressing the role of the biomedical in this process. It is a literary research conducted based on national and international scientific articles, monographs, laws and books that were selected using as a criterion the approach of the chosen theme. We used as research sources the sites SCIELO (Scientific Electronic Library Online), Pubmed, Virtual Library of the Ministry of Health and books present in the physical and virtual library of the Educational Institute Santa Catarina (IESC). Transfusion therapy is a great option to treat the complications of sickle cell anemia, but measures should be used to prevent post-transfusion problems.

Keywords: Sickle cell anemia; Alloimmunization; Transfusion.

\section{Topic: Hematologia e Hemoterapia}

Reviewed anonymously in the process of blind peer.
Received: 20/11/2018

Approved: 22/01/2019
Rawanderson Ferreira Lima Barros (D)

Faculdade Guaraí, Brasil

http://lattes.cnpq.br/0952285846079180

http://orcid.org/0000-0001-8451-4380

bradforever01@gmail.com

Roniel Resplandes da Silva

Faculdade Guaraí, Brasil

http://lattes.cnpq.br/4395914244084159

confeccoes_mae_filhos@outlook.com

Mara Soares de Almeida Mota (id

Faculdade Guaraí, Brasil

http://lattes.cnpq.br/3061777057739833

http://orcid.org/0000-0002-2068-348

mara.almeida06@gmail.com
Simone Pôssas Andrade
Universidade Federal do Tocantins, Brasil
http://lattes.cnpq.br/0552128506796918

simomissag@hotmail.com
Referencing this:

BARROS, R. F. L.; SILVA, R. R.; MOTA, M. S. A.; ANDRADE, S. P..

Transfusão de hemácias em pacientes falcêmicos. Scire Salutis, v.9, n.1, p.50-61, 2019. DOI: http://doi.org/10.6008/CBPC22369600.2019.001.0007

DOI: 10.6008/CBPC2236-9600.2019.001.0007 


\section{INTRODUÇÃO}

A anemia falciforme é uma anemia hemolítica consequente da criptografia da cadeia beta de globina, uma alteração específica no DNA do portador. Ela é de natureza autossômica recessiva encontrada em pessoas que possuem os alelos do gene idênticos para Hemoglobina S (HbS) (GIGLIO et al., 2007; MONTEIRO et al., 2015).

A hemoglobina é o principal elemento que compõe as hemácias, células sanguíneas de formato bicôncavo que não possuem núcleo e que são encarregadas pela condução de oxigênio $\left(\mathrm{O}_{2}\right)$ ao longo do organismo humano. O órgão responsável por produzir essas hemácias é a medula óssea. Alterações nos genes alfa, beta, gama ou delta, resultam em anormalidades nas hemoglobinas fazendo com que elas obtenham um formato diferente dificultando a atividade funcional da hemácia (LORENZI, 2006).

A hemoglobina $S(S=$ sickling = falcização) é caracterizada por conter mutação no gene da cadeia beta, onde a valina substituí o ácido glutâmico que está posicionado no códon 6 . Isso faz com que ela seja insolúvel em baixa tensão de oxigênio, sendo polimerizada dentro da hemácia transformando-a em drepanócito (hemácia em forma de foice). A hemoglobina S possui baixa afinidade por oxigênio, fornecendo este gás a uma tensão fracionada em relação a hemoglobina normal. O quadro anêmico ocorre pela redução e hemólise das hemácias. Em comparação com outras doenças desta classe, a anemia falciforme é a que ocorre com mais regularidade, mais verificado na África Tropical. No Brasil, por exemplo, a anemia é mais evidente em pessoas negras e mulatas (GIGLIO et al., 2007; LORENZI, 2006; MAROUF, 2007; MONTEIRO et al., 2015).

A transfusão sanguínea é um método importante para tratar pessoas com a anemia falciforme. Isso reduz o percentual de hemácias falciformes na corrente sanguínea o que eleva a eficácia de transporte do oxigênio. Porém, a transfusão não é recomendada em caso de anemia basal e outras situações em que a transfusão não seja necessária. Alguns casos como crises dolorosas são comuns em hospitais e são resultantes da obstrução de vasos sanguíneos pelos drepanócitos, tendo como tratamento a hidratação e medicação por analgésicos. A transfusão de hemácias não é um método completamente seguro, embora sejam realizadas provas pré-transfusionais específicas, ela pode ocasionar problemas ao longo do tempo (GONÇALVES et al., 2007; MAROUF, 2007).

Com base nisso surge a seguinte problemática: Por que o paciente falciforme, pode apresentar problemas com a terapia transfusional? Devido a frequência de transfusões, o paciente falcêmico pode sofrer uma aloimunização contra antígenos de vários sistemas de grupos sanguíneos. A melhor forma de prevenir esse tipo de reação é realizando a fenotipagem das hemácias para teste de compatibilidade. Desta forma justifica-se esse trabalho pela dificuldade que existe em encontrar bibliografias que abordam especificamente esse tema, o que torna essa pesquisa uma contribuição importante para a construção do conhecimento, além de orientar profissionais que atuam na área e portadores da doença, considerando que esses pacientes recebem uma quantidade elevada de transfusões. 
O presente estudo tem como objetivo geral abordar sobre a transfusão de hemácias em pacientes falcêmicos; e objetivos específicos, relatar sobre a anemia falciforme; descrever sobre a terapia transfusional e as reações transfusionais em pacientes falcêmicos; citar os principais diagnósticos da anemia falciforme; caracterizar a hemácia fenotipada; discorrer sobre os sistemas Kell, Duffy, Kidd e MNS; e informar sobre a atuação do profissional biomédico no processo de transfusão de sangue.

O seguinte estudo se trata de uma pesquisa literária realizada com base em artigos científicos nacionais e internacionais, monografias, leis e livros que foram selecionados utilizando como critério a abordagem do tema escolhido. A pesquisa ocorreu entre os meses de fevereiro a outubro de 2018. Em relação aos artigos científicos, foram pesquisados 87 artigos, dentre os quais foram escolhidos 13 que apresentavam informações melhores e mais precisas acerca da terapia transfusional em pacientes que possuem anemia falciforme, priorizando as publicações dos últimos dez anos.

Foram utilizados como fontes de pesquisa os sites, SCIELO (Scientific Electronic Library Online) e Pubmed, Biblioteca Virtual do Ministério da Saúde e livros presentes na biblioteca física e virtual do Instituto Educacional Santa Catarina - IESC, utilizando as seguintes palavras chaves: anemia falciforme, aloimunização e transfusão.

\section{REVISÃO TEÓRICA}

\section{Anemia Falciforme}

Anemia falciforme é uma doença hereditária monogênica, atingindo principalmente afrodescendentes. Ela é considerada muito comum no Brasil, assim como é uma das doenças hereditárias mais frequentes no mundo, ocorrendo tanto nos homens quanto nas mulheres, a anemia falciforme tem uma maior predominância Norte e Nordeste do país. Esta anemia causa grandes transtornos na vida dos pacientes e de suas famílias (BRASIL, 2015; SIMÕES et al., 2010).

A anemia é decorrente de uma modificação no gene responsável pela produção da hemoglobina $\mathrm{A}$ ( $\mathrm{HbA})$ ocasionando a produção de HbS. A hemoglobina S é caracterizada por conter mutação no gene da cadeia beta, onde a valina substituí o ácido glutâmico posicionado no códon 6 da cadeia tornando a HbS insolúvel em baixa tensão de oxigênio, sendo polimerizada dentro da hemácia transformando-a em um drepanócito (hemácia em forma de foice ou lua crescente). O paciente pode ser homozigoto (SS) ou heterozigoto (AS) com a existência da hemoglobina S.

Os pacientes heterozigotos (AS) conhecidos como portadores do traço falciforme não sentem nenhum sintoma aparente da doença que é caracterizada apenas em pacientes SS. Para que isso ocorra, a pessoa precisa receber um gene de $\mathrm{HbS}$ de cada um dos pais. Portanto, o paciente com o traço falciforme deve receber orientação genética como forma de prevenção da doença em sua descendência (BRASIL, 2015; GIGLIO et al., 2007; LORENZI, 2006).

A transformação da morfologia das hemácias em drepanócitos é a causa de todos os problemas fisiopatológicos da anemia falciforme, isso porque as hemácias tornam-se enrijecidas perdendo toda sua 
flexibilidade, além de apresentarem uma sobrevida bem menor do que hemácias normais facilitando sua destruição, o que causa a anemia crônica. A anemia falciforme tem um quadro clínico bem variável, sendo os mais comuns na anemia, crises dolorosas agudas, sequestro esplênico, acidente vascular cerebral, síndrome torácica aguda, disfunção pulmonar e renal crônica, levando a uma expectativa de vida reduzida. As manifestações clínicas podem ocorrer já no primeiro ano de nascimento (BRASIL, 2015; SIMÕES et al., 2010).

Essa doença se torna extremamente grave quando não cuidada corretamente, apresentando uma taxa de mortalidade alta, em particular na faixa etária de 0 a 5 anos. É também vista como uma patologia degenerativa, destacando que sem acompanhamento adequado as crises tornam-se frequentes e irão aos poucos debilitando os órgãos, ocasionando algumas lesões que com o passar do tempo se tornam muitas vezes irreversíveis. $O$ acidente vascular cerebral $(A V C)$, a falência de órgãos como a insuficiência renal e a crise vaso-oclusiva aguda são as causas de óbitos mais frequentes (DIAS, 2013; SIMÕES et al., 2010).

\section{Diagnóstico da Anemia Falciforme}

A identificação da doença pode iniciar-se através do diagnóstico de um hemograma apontando anemia grave associada a identificação de drepanócitos em esfregaço sanguíneo, além da contagem elevada de reticulócitos (presente em anemias hemolíticas) e aumento da bilirrubina indireta. A triagem pode ser feita através do Teste de Falcização e Teste Solubilidade, porém apenas confirma a presença da hemoglobina S, não distinguindo se o paciente é heterozigoto (AS) ou homozigoto (SS) para a hemoglobina. Deste modo, estes testes não confirmam a anemia falciforme, visto que a anemia falciforme é autossômica recessiva (homozigotos para HbS) e há portadores assintomáticos do traço falciforme (heterozigotos) que não são anêmicos. Neste caso, para confirmação da doença, é realizada a eletroforese de hemoglobina que evidencia a hemoglobina $S$ além de um aumento na hemoglobina fetal (BATISTA et al., 2005).

O diagnóstico precoce da anemia falciforme é fundamental para iniciar os cuidados com o paciente. O diagnóstico neonatal, por exemplo, possibilita um melhor planejamento de medidas específicas para o tratamento. Para realização desse teste, são coletadas algumas gotas de sangue da criança. A coleta é feita no calcanhar, o que dá o nome popular ao teste (teste do pezinho) (BRASIL, 2015).

\section{Terapia transfusional na Anemia Falciforme}

A transfusão de eritrócitos representa um dos recursos essenciais na terapia dos pacientes com anemia falciforme, assim dando uma melhor sobrevida apesar de algumas contrariedades associadas com a doença. A transfusão em pacientes com anemia falciforme proporciona a redução da parcela de HbS por diluição e aumento do hematócrito com supressão relativa da produção de hemácias e assim diminuição da produção de hemoglobina $S$, acarretando uma considerável melhora no transporte de oxigênio para os tecidos e precavendo os efeitos na vascularização referentes à falcização (JUNQUEIRA et al., 2009).

Em situações mais críticas da doença, a diminuição da hemoglobina é capaz de desempenhar uma incapacidade de o organismo reestabelecer o equilíbrio da atividade cardiorrespiratória o que deixa o 
paciente com risco de vida. Nestes casos, a transfusão de hemácias é de bastante relevância sendo também recomendada em casos de sequestro esplênico, acidente vascular cerebral (AVC), síndrome torácica aguda, entre outras complicações da anemia falciforme.

No entanto, deve-se evitar a transfusão de hemácias como tratamento rotineiro para esses pacientes, e, segundo a Agência Nacional de Vigilância Sanitária (ANVISA), esse tratamento é contraindicado em casos de anemia assintomática, crises dolorosas não complicadas, infecções que prejudiquem a sobrevida ou no alojamento de necroses assépticas, desta forma, evita-se possíveis reações alérgicas, infecções por vírus, sobrecarga de ferro, entre outros problemas (BATISTA et al., 2005).

As transfusões de hemácias têm por finalidade fazer com que a concentração de HbS fique menor que $30 \%$, além de manter a hemoglobina final entre 10 e 12/dL. As hemácias utilizadas nas transfusões devem ter sido colhidas no mínimo em menos de 10 dias antes da transfusão. Além disso, é necessária a filtragem ou lavagem (para retirada de leucócitos) do concentrado de hemácias que será recebido, para reduzir as reações transfusionais não hemolíticas, não excluindo fenotipagem eritrocitária. As hemácias utilizadas na transfusão devem ser negativas para hemoglobina S. As transfusões devem seguir a medida de $10 \mathrm{~mL} / \mathrm{kg}$ porém não ultrapassando o volume máximo de 300mL (BRASIL, 2009, 2012).

Nos casos de crise de dor, a transfusão de hemácias só é recomendada se houver uma baixa de hemoglobina $(\mathrm{Hb})$ maior que $20 \%$ comparada ao valor basal. A síndrome torácica aguda é tratada com transfusão de hemácias nos seguintes casos: se a pressão parcial do oxigênio no sangue arterial ( $\mathrm{PaO} 2)$ estiver abaixo de $70 \mathrm{mmHg}$; diminuição de $25 \%$ do nível basal da pressão parcial do oxigênio no sangue arterial (PaO2); casos de insuficiência cardíaca, congestiva ou direita aguda; pneumonia ligeiramente evolutiva; e dificuldade de respiração com aceleração do ritmo respiratório. No sequestro esplênico a transfusão de hemácias deve ocorrer se for preciso corrigir a hipovolemia aumentando a concentração de hemoglobina para $9-10 \mathrm{~g} / \mathrm{dL}$, mas para tratamento de crianças de até 5 anos de idade, é indicado um programa de transfusão crônica ou hipertransfusão para manter a hemoglobina S menor que 30\% (BRASIL, 2012).

Cerca de um décimo da população com anemia falciforme sofre Acidente Vascular Cerebral (AVC) que acontece quando há um entupimento de artérias do cérebro. Portanto deve-se realizar a exsanguíneo transfusão rapidamente caso haja suspeita de AVC, e, após isso, adotar o programa de transfusão crônica com a finalidade de que a hemoglobina $S$ fique $<50 \%$. No Priaprismo (ereção dolorosa do pênis) a exsanguíneo transfusão parcial ou transfusão simples é indicada caso os exercícios e outros métodos analgésicos não apresentarem melhora em 24 horas (BRASIL, 2012).

O exsanguíneo transfusão parcial é uma opção de tratamento mais aconselhável em alguns casos pois promove a diminuição da concentração de hemoglobina $S$ além de reduzir a hiperviscosidade sanguínea. Esse tratamento pode ser utilizado em algumas complicações da anemia falciforme. Quando o procedimento é realizado no indivíduo adulto, é retirado $300 \mathrm{~mL}$ de sangue com simultânea reposição de solução fisiológica à $0,9 \%$, realizando a transfusão de hemácias em um volume de $300 \mathrm{~mL}$. A exsanguíneo transfusão parcial também pode ser realizada em criança, entretanto é necessário verificar o volume sanguíneo para não retirar mais que $10 \%$ do total que é em torno de $7 \mathrm{~mL} / \mathrm{kg}$ (BRASIL, 2009). 


\section{Reações transfusionais em pacientes falcêmicos}

A transfusão de eritrócitos é muito utilizada para tratar e prevenir complicações da anemia falciforme. Metade desses pacientes passam por transfusão sanguínea em certo tempo da sua vida. A finalidade desse tratamento é aumentar a eficácia da condução e oxigênio ao longo do organismo além de melhorar também a fluidez sanguínea. Isso faz com que o percentual de HbS diminua de forma que o hematócrito seja elevado, contudo sem que este exceda $30 \%$ para prevenir vaso-oclusões significativas. No entanto, apenas ser portador da anemia não sugere a transfusão de hemácias devido aos riscos inerentes que os pacientes são expostos. Por isso é necessário ter muito cuidado ao se recorrer às transfusões (BRASIL, 2012; PINTO et al., 2011).

Os pacientes portadores da anemia falciforme precisam rotineiramente de transfusões devido às complicações relacionadas à doença. Porém, apesar de ser uma forma significativa de tratamento, as frequentes transfusões podem trazer um risco à saúde do paciente, fato este que torna a utilização da terapia transfusional bem cautelosa. Uma das complicações mais frequentes da transfusão sanguínea em pacientes falciformes é a aloimunização contra antígenos das hemácias. Isso pode ocorrer em cerca de 1/4 (um quarto) dos pacientes que estejam no sistema de transfusão crônica.

A característica principal dessa reação é o aparecimento de aloanticorpos. Os aloanticorpos são imunoglobulinas que o sistema imune produz contra um antígeno eritrocitário. Estes aloanticorpos causam reações transfusionais hemolíticas agudas, tornando a aquisição de hemácias compatíveis mais complicada. O índice de aloimunização em pacientes falciformes é bem maior quando comparado ao de outras populações que recebem transfusão crônica. A ocorrência de aloimunização é resultado da grande variedade de antígenos presentes no sangue de doadores e pacientes.

Segundo Scheunemann et al. (2010), a aloimunização pode estar associada a idade, sexo e quantidade de unidades transfusionais recebidas. Scheunemann et al. (2010) ainda sugere que as mulheres apresentam maior taxa de aloimunização do que homens devido a maior regularidade de transfusões. Esses antígenos são capazes de induzir a formação de aloanticorpos IgG que reagem em uma temperatura de $37^{\circ} \mathrm{C}$ e são capazes de causar reações hemolíticas em pacientes que receberam transfusão, podendo resultar na morte destes em casos mais graves (BRASIL, 2013a; PESSONI et al., 2018; PINTO et al., 2011).

Em um estudo realizado por Pinto et al. (2011), observou-se que, dos pacientes que foram transfundidos mais de dez vezes, $80 \%$ apresentaram aloimunização. Já em outro estudo feito por Helman et al. (2011), notou-se que pacientes que receberam mais de cinco transfusões de hemácias tem um grande risco de sofrer a aloimunização. Em relação ao sexo do paciente, não foram observadas diferenças, exceto pelas mulheres que tiveram mais de três gestações. Chou et al. (2013) observou em estudo que de 58\% dos pacientes com anemia falciforme que estavam sobre programa de transfusão crônica sofreram aloimunização, e 15\% dos pacientes falciformes que receberam transfusões ocasionais também sofreram aloimunização. 
Porém notou-se que os pacientes aloimunizados receberam mais transfusões do que os não imunizados. As taxas de aloimunização em indivíduos com anemia falciforme é de 18,7\% comparadas a doadores saudáveis que está entre 0,009\% e 0,06\% (PESSONI et al., 2018). A aloimunização está ligada a alguns fatores como: desigualdades entre os antígenos de quem doa e quem recebe as hemácias, frequências transfusionais e idade dos pacientes. Um método importante para reduzir o perigo de aloimunização, e, consequentemente, de reações transfusionais hemolíticas em pacientes falcêmicos, é a fenotipagem sanguínea que é realizada nos pacientes e doares.

Os sistemas Rh, Kiddy, Kell, Duffy e MNS são observados com mais frequência nesses processos. Infelizmente alguns aloanticorpos não são identificados durante a pesquisa devido a problemas como, baixa quantidade de anticorpos, falta do antígeno na placa de testes, etc. A não identificação desses antígenos pode levar a um maior risco de reações hemolíticas tardias pós transfusão devido a não seleção adequada de hemácias compatíveis (HELMAN et al., 2011; PESSONI et al., 2018; PINTO et al., 2011).

Em um caso apresentado por Naufel et al. (2012), uma paciente falcêmica recebeu uma transfusão de hemácias para tratar uma crise vaso-oclusiva e em seguida apresentou hemoglobinúria (presença de hemoglobina na urina). Ao realizar o teste de antiglobulina humana - indireto (Coombs indireto), este teve resultado positivo, entretanto não foram detectados os prováveis anticorpos causadores da reação hemolítica. Em um período de quatro anos, a paciente foi transfundida mais duas vezes, não havendo nenhuma alteração em seu quadro.

No ano seguinte, ao receber nova transfusão, apresentou outra crise hemolítica onde foi identificado o anticorpo anti-Fya no seu soro. Em um período de dez anos a paciente recebeu mais duas transfusões, essas negativas para o antígeno Fyạ, não apresentando nenhuma alteração em seu quadro. Porém, após receber outras duas transfusões enquanto esteve internada em um pronto socorro e ter recebido alta, a paciente apresentou sintomas de reação hemolítica e baixa nos seus índices hematimétricos. Recebeu novamente outras duas transfusões negativas para o antígeno Fyạa, apresentando melhora e em seguida recebendo alta após dois dias.

Decorridas 24 horas, a paciente apresentou novamente sintomas de crise hemolítica. Realizou-se o teste de Coombs e Pesquisa de Anticorpos Irregulares (PAI) os quais apresentaram resultados negativos. Após novas transfusões sem êxito na melhora da condição, realizou-se novamente o PAl que identificou novo anticorpo, o anti-C. Novamente a paciente recebeu transfusões, porém negativas para os antígenos Fya e C, apresentando uma pequena melhora, mas seus índices hematimétricos voltaram a cair nos dias seguintes. Após novas pesquisas, foram identificados anticorpos para o antígeno $\mathrm{JK}^{\mathrm{b}}$ no soro da paciente.

Nova transfusão foi realizada, dessa vez negativa para $\mathrm{Fy}^{\mathrm{a}}, \mathrm{C}$ e JK${ }^{\mathrm{b}}$ fazendo com que os índices hematimétricos da paciente subissem, porém com uma baixa após 48 horas. As transfusões foram evitadas e após 12 dias de internação, a paciente apresentou melhoras em seu quadro. Nota-se a dificuldade em determinar a fenotipagem correta de antígenos eritrocitários, o que aumenta o risco de reações hemolíticas.

Em um estudo realizado por Pessoni et. al. (2018), notou-se que pacientes com anemia falciforme sofreram aloimunização mesmo com a fenotipagem sanguínea. Pessoni et al. (2018) também aponta que 
outras pesquisas mostraram a aloimunização nesses pacientes falcêmicos apesar das medidas profiláticas de fenotipagem sanguínea. A diminuição da terapia transfusional em paciente falcêmicos associada à maiores combinações de fenótipos sanguíneos são importantes para a redução de aloimunizações (SCHEUNEMANN et al., 2010).

Outra reação transfusional que pode ocorrer em pacientes com anemia falciforme é a sobrecarga de ferro. Esses pacientes que necessitam de transfusões periódicas ou esporádicas normalmente apresentam sobrecarga de ferro devido as frequentes transfusões. O corpo humano é incapaz de elevar a eliminação de ferro, isso faz com que o organismo tenha uma sobrecarga em caso de múltiplas transfusões. Dessa forma o ferro é acumulado nos tecidos resultando em danificação do tecido além de deficiência funcional e fibrose, sobretudo no fígado, miocárdio, medula óssea, baço, glândulas endócrinas e miocárdio (CANÇADO, 2007).

\section{Hemácia fenotipada}

Atualmente a hemoterapia vem sendo caracterizada pelo grande avanço e progresso em tecnologias, nisso se encaixa a fenotipagem de hemácias. Esta aponta se há existência ou não de determinados antígenos que são encontrados na região da membrana das hemácias, onde uma prova direta é feita no intuito de se encontrar os antígenos eritrocitários, e em seguida a prova reversa para encontrar e definir os anticorpos do sistema. A área responsável por esta fenotipagem é a imuno-hematologia. Estes testes detectam no soro do paciente, aloanticorpos, além dos antígenos eritrocitários de diversos grupos sanguíneos (BORTOLOTTO, 2011; BRASIL, 2013a).

Os ensaios de imuno-hematologia para pesquisa de antígenos eritrocitários são fundamentados na ligação entre antígeno e anticorpo e o resultado é visualizado de forma macroscópica através da aglutinação. Existem diferentes métodos para a realização dos ensaios sendo um deles o método em coluna de aglutinação. Este método utiliza colunas com microtubos (local onde se dá a aglutinação após a centrifugação) que são preenchidas por um gel fino contendo anticorpos. Um método antigo, porém, eficaz, utilizado até hoje nos bancos de sangue é o método de hemaglutinação em tubo devido esta técnica mostrar resultados fidedignos e de boa reprodutibilidade.

Este método utiliza tubos de vidro onde é colocada a suspensão de hemácias e anticorpos que são incubados e levados à centrifugação para posterior leitura. Outro método utilizado é o de microplaca (método eficaz para grandes rotinas), muito utilizada na pesquisa de anticorpos irregulares. A aglutinação se dá nas cavidades com fundo em forma de "U" (BRASIL, 2013a).

O sistema Rh foi criado por volta de 1940 por Landisteiner e Alexandre Wiener, depois de inserir sangue de um macaco em coelhos, notaram que havia uma reação que ocasionava a formação de um anticorpo denominado anti-RH, que desde então vem sendo o maior sistema de grupos sanguíneo, sendo identificados 49 antígenos, que são de exclusividade das hemácias, não podendo serem encontrados em plaquetas ou leucócitos. O sistema $A B O$ é o de maior importância clínica para os bancos de sangue. Esse sistema tem sua fenotipagem definida pelos antígenos encontrados em seus eritrócitos e seus anticorpos oriundos do seu soro (BORTOLOTTO, 2011). 
A fenotipagem sanguínea é muito importante para previr a aloimunização, uma complicação comum para o processo transfusional, principalmente em pacientes falciformes. Alguns estudos mostram que $18 \%$ a $36 \%$ dos pacientes com anemia falciforme acabam sendo aloimunizados, sendo que a maioria desses anticorpos produzidos possui natureza transitória (NAOUM et al., 2004).

\section{Os sistemas Kell, Duffy, Kidd e MNS}

Existem mais de 29 sistemas de antígenos nas hemácias, dentre eles, os mais significativos são: ABO, Rh (Rhesus), Kiddy, Kell, MNS e Duffy. Cada sistema sanguíneo constitui um grupo de antígenos semelhantes em suas características. Os antígenos das hemácias ficam localizados em sua superfície e são chamados de aloantígenos, sendo disseminados de forma hereditária. Eles possuem a capacidade de provocar a produção de anticorpos que se ligam a eles. A manifestação dos antígenos eritrocitários na superfície das hemácias é chamada de fenótipo eritrocitário. A compreensão desse assunto se faz importante principalmente nos processos de transfusões de hemácias (BRASIL, 2013a; LORENZI, 2006).

O sistema K1 (Kell) é um dos três mais importantes sistemas dentro do processo de transfusão e se encontra presente em uma pequena parcela da população, no entanto o antígeno k (cellano) é encontrado em cerca de $99 \%$. O anticorpo desse antígeno foi retratado pela primeira vez por Coombs e sua equipe em 1946, quando observaram que um recém-nascido apresentou sensibilização pelos anticorpos da mãe (BORTOLOTTO, 2011; SILVA, 2016).

Os antígenos do sistema Duffy são bastante significativos no cotidiano dos hemocentros, sendo seus antígenos o $\mathrm{Fy}^{\mathrm{a}}$ e $\mathrm{Fy}^{\mathrm{b}}$. O nome Duffy foi em consideração a um paciente com hemofilia que recebeu várias transfusões. Esses antígenos são considerados monogênicos e podem causar uma reação imunológica moderada. Os anticorpos contra esse grupo são menos recorrentes que os do sistema Kell e podem surgir correlacionados com outros de grupos sanguíneos diferentes. Entretanto, os anticorpos do sistema Duffy estão relacionados com reações hemolíticas, principalmente em pessoas $\mathrm{Fy}^{(\mathrm{a}-\mathrm{b}-)}$ com anemia falciforme (SILVA, 2016).

O sistema Kidd recebeu esse nome em homenagem a um paciente em que foi descoberto o grupo.

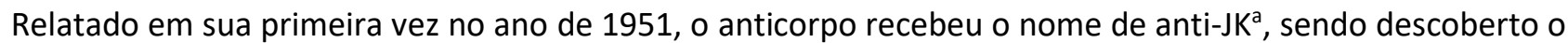
antígeno $\mathrm{JK}^{\mathrm{b}}$ dois anos depois. Os anticorpos anti-JK ${ }^{\mathrm{a}}$ e anti-JK ${ }^{\mathrm{b}}$ são de difíceis de serem detectados, por isso esse grupo possui uma importância clínica singular no dia a dia dos hemocentros considerando que esses anticorpos estão envolvidos rotineiramente em reações hemolíticas transfusionais (SILVA, 2016).

O sistema MNS possui mais 40 antígenos e é uns dos mais complexos, ficando atrás apenas do Sistema Rh. Dentre esses antígenos somente cinco tem importância clínica ( $M, N, S$, s e U), porém são pouco relatados. Os primeiros anticorpos desse sistema (anti-M e anti-N) foram detectados em 1927, depois que o sistema $A B O$ foi descoberto. As pesquisas eram feitas em coelhos que eram imunizados com hemácias de humanos. O anticorpo mais frequente é o anti-M. Na transfusão, em caso de incompatibilidade com esse sistema, o paciente poderá sofrer alguma reação decorrente desta transfusão, que pode ser grave em alguns casos (OLIVEIRA et al., 2013; VERRASTRO, 2005). 


\section{Atuação do profissional biomédico no processo de transfusão de sangue}

Conforme Resolução no78/02, datada de 29 de abril de 2002, modificada pela Resolução nำ227/13, datada de 07 de maio de 2013, que define a área de atuação Profissional do Biomédico, este pode possuir habilitação para trabalhar em Análises Clínicas assim como em Banco de Sangue podendo assumir e realizar a manipulação do sangue, testes sorológicos e pré-transfusionais. O biomédico também pode ser responsável técnico e de direção nas atividades anteriormente mencionadas, e, segundo a Lei 6.684, de 03 de setembro de 1979, o biomédico pode atuar em serviços de hemoterapia, sob supervisão médica (BRASIL, 1979, 2002, 2013b).

Nesse sentido, observa-se que a definição eficaz do tipo sanguíneo é de grande importância para evitar complicações durante as transfusões de sangue. A hemoterapia pode ser tanto benéfica quanto pode trazer perigos ao paciente que está sob tratamento. As respostas adversas a esse tratamento é uma das principais dificuldades encontradas pelos agentes da área da saúde responsáveis pelo processo de transfusão. A aloimunização contra os antígenos das hemácias é um dos fatores que mais complicam a transfusão sanguínea, principalmente em pessoas que possuem a anemia falciforme, pois a taxa de ocorrência nestes pacientes ocorre em torno de 6 a 36\% dos casos (GOMES, 2014; MARTINS et al., 2009).

Nos hemocentros, tanto em receptores e doares de sangue, é indispensável a pesquisa de anticorpos que tenham significado clínico importante. A fenotipagem desses eritrócitos deve ser feita para buscar os grupos de antígenos que possuem significados clínicos mais importantes e que podem produzir aloanticorpos. Durante a triagem clínica, também é necessário a aferição da concentração de hemácias e hematócrito, contagem de plaquetas, leucócitos procedimentos que podem ser realizados por biomédicos habilitados em análises clínicas (BRASIL, 2013a). Portanto o Biomédico é um profissional capacitado para atuar nesses hemocentros realizando todos os procedimentos de processamento do sangue, além dos exames pré-transfusionais e análises clínicas referentes à transfusão (BRASIL, 1979, 2002, 2013b).

\section{CONSIDERAÇÕES FINAIS}

A anemia falciforme é uma doença que necessita de cuidados especiais devido às suas complicações. A terapia transfusional é uma ótima opção de tratamento das complicações agudas desta anemia. Sua principal função é a diminuição da porcentagem de hemoglobina S no sangue do portador da anemia, além do aumento do hematócrito e da concentração de hemoglobina total. Infelizmente, como a maioria das terapias, a terapia transfusional pode trazer complicações ao paciente. Dentre as complicações mais frequentes, está a aloimunização contra antígenos eritrocitários que implicam em reações hemolíticas que podem gerar grandes transtornos ao paciente ou até mesmo a morte.

O método mais eficaz para prevenir a aloimunização é a fenotipagem eritrocitária. O aperfeiçoamento da fenotipagem eritrocitária pode reduzir ainda mais o risco de aloimunização considerando a grande quantidade existente de grupos sanguíneos. O biomédico é um profissional capacitado para atuar nos bancos de sangue assim como em testes pré-transfusionais sendo bastante 
importante no processo transfusional. Desta forma, o biomédico pode ajudar atuando em pesquisas para aperfeiçoar o processo da fenotipagem sanguínea e assim diminuir as complicações da terapia transfusional.

\section{REFERÊNCIAS}

BATISTA, A.; ANDRADE, T. C.. Anemia falciforme: um problema de saúde pública do Brasil. Universitas: Ciências da Saúde, Brasília, v.3, n.1, p.83-89, 2005.

BORTOLOTTO, A. N. S.. Prevalência e fenotipagem eritrocitária em doadores de sangue no hemocentro regional de Santa Maria. Dissertação (Mestrado em Ciências Farmacêuticas) - Universidade Federal de Santa Maria, Santa Maria, 2011.

\section{BRASIL. Lei n.6684 de 03 de setembro de 1979.}

Regulamenta as profissões de Biólogo e de Biomédico, cria o Conselho Federal e os Conselhos Regionais de Biologia e Biomedicina, e dá outras providências. Brasília: DOU, 1979.

BRASIL. Ministério da Saúde. Doença falciforme: condutas básicas para tratamento. Brasília: MS, 2012.

BRASIL. Ministério da Saúde. Doença falciforme: diretrizes básicas da linha de cuidado. Brasília: MS, 2015.

BRASIL. Ministério da Saúde. Manual de eventos agudos em doença falciforme. Brasília: MS, 2009.

BRASIL. Ministério da Saúde. Técnico em hemoterapia: livro texto. Brasília: MS, 2013.

BRASIL. Resolução n.227 de 07 de maio de 2013. Dá nova redação ao inciso II do artigo 20 da Resolução n.78 de 29 de abril de 2002. Brasília: DOU, 2013.

BRASIL. Resolução n.78 de $\mathbf{2 9}$ de abril de 2002. Dispõe sobre o Ato Profissional Biomédico, fixa o campo de atividade do Biomédico e cria normas de Responsabilidade Técnica. Brasília: DOU, 2002.

CANÇADO, R. D.. Sobrecarga e quelação de ferro na anemia falciforme. Revista Brasileira de Hematologia e Hemoterapia, São José do Rio Preto, v.29, n.3, p.316326, 2007.

CHOU, S. T.; JACKSON, T.; VEGE, S.; SMITH-WHITLEY, K.; FRIEDMAN, D. F.; WESTHOFF, C. M.. High prevalence of red blood cell alloimmunization in sickle cell disease despite transfusion from Rh-matched minority donors. Blood, Washington, v.122, n.6, p.1062-1071, 2013. DOI: http://doi.org/10.1182/blood-2013-03-490623

DIAS, A. L. A.. A (Re)construção do caminhar: itinerário terapêutico de pessoas com Doença Falciforme com histórico de úlcera de perna. 2013. (Mestrado em Saúde Coletiva) - Universidade Federal da Bahia, Salvador, 2013.

GIGLIO, A. D.; KALINS R.. Princípios de Hematologia Clínica. Barueri: Manole, 2007

GOMES, G. G.. Avaliação de aloimunização e autoimunização eritrocitária em crianças portadoras de anemia falciforme, indicadas ao regime de hipertransfusão por doppler transcraniano alterado ou acidente vascular encefálico instalado. Monografia (Graduação em Medicina) - Universidade Federal da Bahia, Salvador, 2014.

GONÇALVES, C.; MARQUES, J. S.; RODRIGUES, H. L. Drepanocitose: Novas perspectivas da abordagem terapêutica. Boletim da SPHM, v.22, n.4, p.5-27, 2007.

HELMAN, R.; CANÇADO, R. D.; OLIVATTO, C.. Incidence of alloimunization in sickle cell disease: experience of a center in São Paulo. Einstein, São Paulo, v.9, n.2, p.160-164, 2011. DOI: http://doi.org/10.1590/S1679-45082011AO2003

JUNQUEIRA, P. C.; HAMERSCHLAK, N.; ROSENBLIT, J.. Hemoterapia Clínica. São Paulo: Roca, 2009.

LORENZI, T. F.. Manual de Hematologia: Propedêutica e Clínica. 4 ed. Rio de Janeiro: Guanabara Koogan, 2006.

MAROUF, R.. Blood transfusion in sickle cell disease. Hemoglobin, Kuwait, v.35, n.5, p.495-502, 2011. DOI: http://doi.org/10.3109/03630269.2011.596984

MARTINS, M. L.; CRUZ, K. V. D.; SILVA, M. C. F.; VIEIRA, Z. M.. Uso da genotipagem de grupos sanguíneos na elucidação de casos inconclusivos na fenotipagem eritrocitária de pacientes atendidos na Fundação Hemominas. Revista Brasileira de Hematologia e Hemoterapia, v.31, n.4, p.252259, 2009.

MONTEIRO, A. C. B.; DORIGATTI, D. H.; RODRIGUES, A. G.; SILVA, J. B. M.. Anemia falciforme, uma doença caracterizada pela alteração no formato das hemácias. Saúde em Foco, Amparo, v.7, p.107-118, 2015.

NAOUM, P. C.; NAOUM, F. A.. Doença das células falciformes. São Paulo: Sarvier, 2004.

NAUFEL, C. C. S.; BRAGA, J. A. P.; CANÇADO, R. D.; JUNIOR, D. M. L.; BORDIN, J. O.. Reação transfusional hiperhemolítica em pacientes portadores de anemia falciforme: Relato de dois casos. Revista Brasileira de Hematologia e Hemoterapia, São José do Rio Preto, v.24, n.4, p.292-299, 2002.

OLIVEIRA, M. S. C.; RIBEIRO, F. C.; VIZZONI, A. G.. Conceitos básicos e aplicados em imuno-hematologia. Rio de Janeiro: EPSJV, 2013.

PESSONI, L. L.; FERREIRA, M. A.; SILVA, J. C. R.; ALCANTARA, K. C.. Red blood cell alloimmunization among hospitalized patients: transfusion reactions and low alloantibody identification rate. Hematology, Transfusion and Cell Therapy, Goiânia, v.40, n.4, p.326-331, 2018. Dol: http://doi.org/10.1016/j.htct.2018.04.001

PINTO, P. C. A.; BRAGA, J. A. P.; SANTOS, A. M. N.. Risk factors for alloimmunization in patients with sickle cell anemia. Revista da Associação Médica Brasileira, São Paulo, v.57, n.6, p.668-673, 2011. DOI: http://doi.org/10.1590/S0104-42302011000600014 
SCHEUNEMANN, L. P.; ATAGA, K. L.. Delayed hemolytic transfusion reaction in sickle cell disease. American Journal of the Medical Sciences, Raleigh, v.339, n.3, p.266-269, 2010. DOI: http://doi.org/10.1097/MAJ.0b013e3181c70e14

SILVA, J. M.. Fenotipagem Eritrocitária em Doadores de Sangue no HEMOPI (Teresina - Picos) - PI e no Hemocentro Regional de Crato - CE. Dissertação (Mestrado em Farmacologia Clínica) - Universidade Federal do Ceará, Fortaleza, 2016.
SIMÕES, B. P.; PIERONI, F.; BARROS, G. M. N.; MACHADO, C. L.; CANÇADO, R. D.; SALVINO, M. A.; ÂNGULO, I.; VOLTARELLI, J. C.. Consenso Brasileiro em Transplante de Células-Tronco Hematopoiéticas: Comitê de Hemoglobinopatias. Revista Brasileira de Hematologia e Hemoterapia, São Paulo, v.32, n.1, p.46-53, 2010.

VERRASTRO, T.. Hematologia e Hemoterapia: fundamentos de morfologia, fisiologia, patologia e clínica. São Paulo: Atheneu, 2005.

A CBPC - Companhia Brasileira de Produção Científica (CNPJ: 11.221.422/0001-03) detém os direitos materiais desta publicação. Os direitos referem-se à publicação do trabalho em qualquer parte do mundo, incluindo os direitos às renovações, expansões e disseminações da contribuição, bem como outros direitos subsidiários. Todos os trabalhos publicados eletronicamente poderão posteriormente ser publicados em coletâneas impressas sob coordenação da Sustenere Publishing, da Companhia Brasileira de Produção Científica e seus parceiros autorizados. Os (as) autores (as) preservam os direitos autorais, mas não têm permissão para a publicação da contribuição em outro meio, impresso ou digital, em português ou em tradução. 